\title{
Research on the Construction of Logistics Experiment Teaching System and the Improvement of Teaching Quality
}

\author{
ZHANG Xiao-lin \\ Department of Economic and Management, Tianjin \\ Agricultural University, Tianjin 300384, China
}

\author{
ZHANG Xiao-dong \\ Department of Library, Tianjin Agricultural University, \\ Tianjin 300384, China
}

\section{THE MAIN PROBLEMS OF LOGISTICS EXPERIMENT TEACHING}

\begin{abstract}
Logistics experiment teaching is an important part of the cultivation system of logistics talent. At present, the logistics experiment teaching system is faced with the problems, such as lack of systematization, single teaching methods and imperfect evaluation system. To construct logistics experiment teaching system, we need to implement such principles as students-centered teaching method, combination of theoretical teaching and experimental teaching, and step-by-step curriculum. The following measures should be implemented to promote logistics experimental teaching level: optimizing the experimental teaching content, building the complete experimental teaching system, improving experimental teaching methods, optimizing experiment evaluation system, and establishing supporting teacher resources.
\end{abstract}

Keywords-Logistic management; Logistics experiment teaching system; Teaching quality improvement

\section{INTRODUCTION}

Logistics experiment teaching is an important part of the system cultivating logistics professional talent. With the rapid development of economy and society, higher requirements for the practical ability and innovation ability of logistics talent have been put forward. It is crucial to pay attention to the cultivation of students' practical ability to meet the needs of the logistics market. In the process of establishing the teaching system for application-oriented logistics talent cultivation, experimental teaching will play the more and more important role. How to improve the quality of experimental teaching has become an important issue for improving the quality of applied talent. It is necessary to accurately grasp the direction of logistics practical teaching reform and development, establish the systematic logistics experimental teaching system and build the reasonable practical teaching mode of the logistics major. Only when the theoretical teaching and experimental teaching develop in parallel, can we achieve the scheduled cultivation goal.

\section{A. Lack of systematization in experiment teaching}

At present, colleges and universities in our country attach great importance to the construction of logistics laboratory, but the lack of systematization in the construction of logistics laboratory and logistics experiment teaching is a common problem. Constructing the logistics laboratory, colleges and universities often do not have systematic planning for experimental teaching system and also the use of experimental facility and equipment. It gives rise to the problems of low use ratio of facility and equipment of logistics as well as the failure of setting up the knowledge system structure oriented to the whole logistics process, which resulting in lack of completeness and systematicness in experimental teaching system.

\section{$B$. The single mean of experimental teaching}

The good contents of experimental teaching requires the good teaching method. However, it is a common problem that the experimental teaching method is not rich enough. At present, the teaching of logistics experiment is mainly based on teacher's explanation and on-site demonstration. The students do not have so much time to do their own hands-on operation and discussion with one another that they can not deeply understand the experiment contents. The student-centered heuristic and discussion-based experimental teaching approach is difficult to be implemented, which influences the effect of experimental teaching [1]

\section{The imperfect system of experimental evaluation system}

At present, the quality evaluation system of logistics experimental teaching is not perfect, and the diversified and comprehensive evaluation system has not been set up yet. The experimental evaluation is mainly based on the students' experimental report, which is not better combined with the process evaluation. Experimental report plus the attendance makes up the student's experiment scores. This evaluation method is relatively simple, which can't fully and accurately measure the experimental effect of students. 


\section{IDEAS AND PRINCIPLES OF THE CONSTRUCTION OF LOGISTICS EXPERIMENT TEACHING SYSTEM}

The improvement of experiment teaching level firstly is based on the improvement of experimental teaching ideology. The general design of logistics experiment teaching system should be based on the major talent cultivation objectives and major construction planning of logistics management. The experimental teaching system should be established matching the major theory teaching system and adapting to the development of logistics industry. At the same time, the students' creative ability should be put in a prominent position and the major characteristics be strengthened in the teaching system for improving the comprehensive quality and overall level of logistics talent of our country. The following principles should be followed in the construction of logistics experiment teaching system:

\section{A. Being students-centered}

Students are the subjects of learning. Student-centered classes require teachers to fully stimulate the students' learning interests and leads the learning way for students. Cultivating overall-developed talent with practical ability need to be set as the center to establish and perfect the teaching system of logistics experiment, and carry out targeted experimental training to improve their major ability.

\section{B. Combination of theoretical teaching and experimental} teaching

Perfecting integration and mutual promotion between experimental teaching and theoretical teaching is the important measure to improve the teaching quality. It is essential to systematically design logistics experiment teaching system, and build major teaching system of logistics management perfectly integrating theoretical teaching with experimental teaching.

\section{Step-by-step curriculum}

Experimental teaching is not a simple adding of various experimental courses. The design of logistics experimental teaching system should reflect the teaching concept of different phases. The arrangement of logistics experiment courses should accord with the principle of gradual progress from low level to advanced level.

\section{THE MAIN MEASURES OF PROMOTING LOGISTICS EXPERIMENTAL TEACHING LEVEL}

A. Optimizing the experimental teaching content and building the complete experimental teaching system

It is important to lay the foundation for improving the experimental teaching quality by optimizing the contents of experimental teaching and constructing a complete experimental teaching system. Based on the principle of systematization, integration, and the target of cultivating major talent, the experiment content according with different levels should be designed. To enhance practical ability as the core, we must set up the step-by-step curriculum system covering from grasping the basic knowledge and skills to cultivating comprehensive ability and innovative ability. The experimental teaching system can be divided into three parts: the basic experiment module, the specialized experiment module and the comprehensive experiment module.

The basic module includes basic information technology experiments and basic logistics management experiments, which helps students acquire basic theoretical knowledge, master basic operations and develop basic skills. The specialized module mainly includes logistics system simulation, logistics distribution center operation, supply chain management and other professional experiments, which helps students master the professional knowledge and acquire professional practice skills. The comprehensive module includes professional comprehensive design, open experiment, scientific and technological innovation activities, etc. It provides experimental or practical platform for students to carry out innovative practice activities, develop innovative abilities and improve comprehensive quality [1-2] 


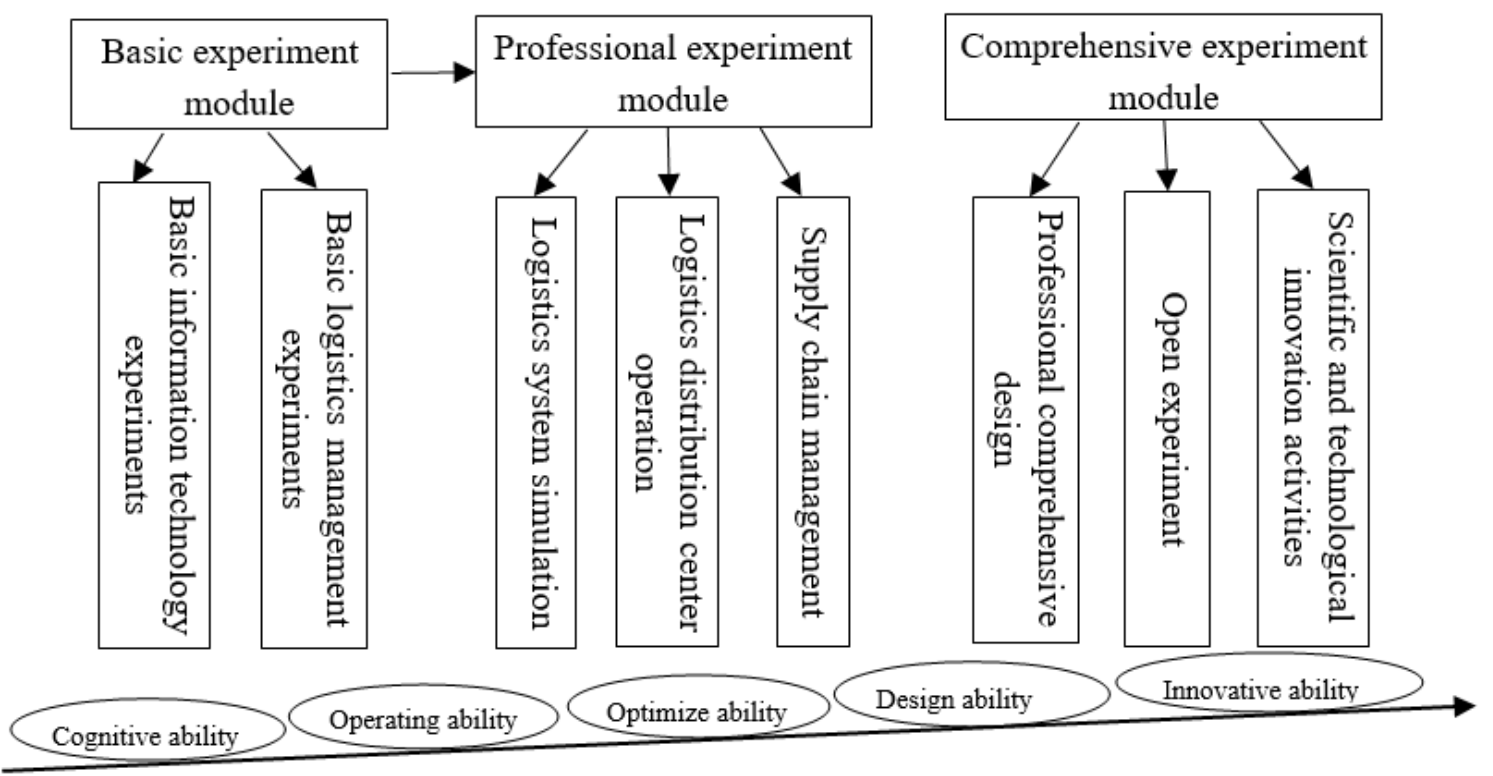

Fig. 1. The experimental teaching system of logistics management

\section{B. Improving experimental teaching methods}

By improving the experimental teaching methods, the students' interest in experiment could be motivated. We should change the traditional teaching mode centered in verification experiment and teacher's explanation, and establish the studentcentered and teacher-led experimental teaching mode which emphasize the design thought during the experiment, integrate the scientific research concept into the experiment, and guide and encourage students to solve practical problems with innovative ideas. The mode focuses on cultivating the students' practical ability from discovering problem and solving problem to summarizing problem by designing experiments independently under the given experiment goal.
Moreover, the resource-rich and function-powerful experimental teaching platform should be set up to support improving the mode and method of experimental teaching. These functions can be achieved through the platform such as online preview, experiment booking, communication between teachers and students, problem feedback and so on, which could accomplish the goal of broadening students' learning space, improving self-learning ability and cultivating innovative thinking ability.

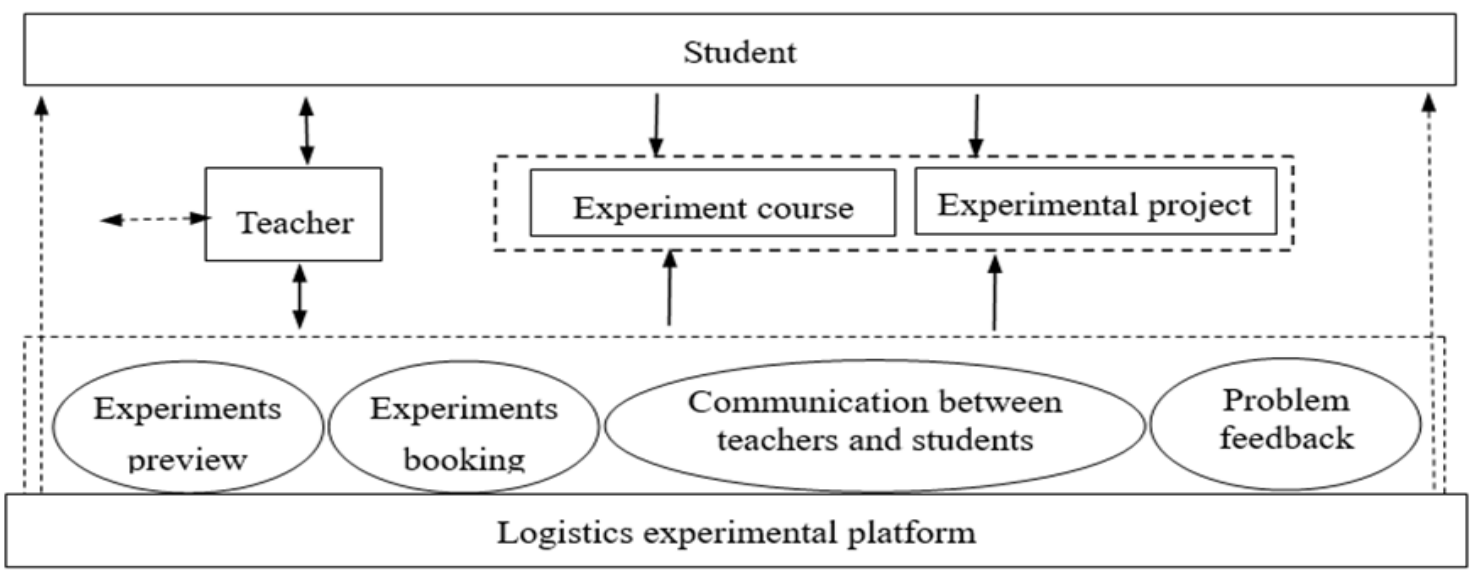

Fig. 2. The experimental teaching platform of logistics management 


\section{Optimizing experiment evaluation system}

Promotion of experimental teaching level requires establishing effective evaluation system of experimental teaching. Adapting to the goal of cultivating major talent, and oriented towards the social talent demands, the experimental teaching evaluation should construct the evaluation system which can reasonably evaluate students' professional knowledge and professional abilities. The evaluation should be an interactive evaluation between teachers and students. At the same time, we should attach importance to the evaluation of the whole process of experimental teaching. Teachers should not make the evaluation results only based on the experimental reports, but should establish a multi-level and diversified evaluation system. Moreover, the teachers are required to give personalized evaluation according to the individual characteristics of students for stimulating students' interests in experimental teaching and promoting the students' abilities to achieve the good effect of experimental teaching.

\section{Establishing the supporting teacher resources}

Only the high-level experimental teaching staff can improve the level of logistics experimental teaching. The competent experimental teachers need a good command of the solid theoretical foundation, the strong practical ability, and the diversified teaching methods. The system of experimental teachers should be established with "academic leaders as the core, full-time and part-time experimental teachers as the basis and extra-school resources as the supplement" [3].

\section{CONCLUSION}

In short, experimental teaching is becoming more and more important in the cultivating logistics talent. Universities must create student-centered experimental teaching system of logistics management with advanced functions and representing the development trend of modern logistics, and continuously explore the experimental teaching methods and means suitable for the talent cultivation of logistics management to promote the quality of talent cultivation.

\section{REFERENCES}

[1] Fu Peihua, Peng Yang, Li Xiulin. Study and Construction of"3+3"Experiment Teaching System for Logistics Management Specialty [J]. Logistics Technology, 2015,34(1):303-305.

[2] ZHOU Xiao-fen, WANG Yong, ZHU Shu-fan. Explore the Design Ideas of Applied Logistics Management Professional Experimental Teaching Curriculum system [J]. Logistics Engineering and Management, 2015, 37(11): 290-291.

[3] ZHOU Xiao-fen, ZHU Rong-yan, LENG Fu-chen.Research on Experimental Course System for the Application-oriented Logistics Management Undergraduate: Taking Logistics Management Major of Wuhan Technology and Business College as an example[J]. Logistics Engineering and Management, 2015, 37 (9): 222-223. 